\title{
Time course and regional distribution of cortical changes during acute
}

\section{alcohol ingestion}

Yvonne Tran, Ph.D. ${ }^{1}$ Ashley Craig, Ph.D. ${ }^{1}$ Roger Bartrop, M.D. ${ }^{2}$ and Graham Nicholson, Ph.D. ${ }^{1}$

1. Department of Health Sciences, University of Technology, Sydney, NSW Australia

2. Department of Psychological Medicine, Royal North Shore Hospital, St Leonards, NSW Australia

Address correspondence to Dr Yvonne Tran, Department of Health Sciences, University of Technology, Sydney, NSW Australia; email: Yvonne.Tran@uts.edu.au

This research has been supported by a competitive grant from the New South Wales, Motor Accident Authority, Australia.

This paper has not been published elsewhere and has not been submitted simultaneously for publication elsewhere. 


\begin{abstract}
Behavioral effects of alcohol are known to be greater when the blood alcohol is rising, known as the Mellanby effect, however, research investigating the cortical changes during this period is scarce. The objective of this study was to investigate the effects of consumption of alcohol on cortical activity measured by the electroencephalogram (EEG) during the absorption or rising phase of alcohol. EEG signals were recorded using the entire 10/20 montage system. The experimental design consisted of a repeated measures randomized crossover design in which subjects acted as their own control. This involved recording two EEG baseline measures, each of which was followed by a placebo or alcohol condition, delivered over two days for ten subjects. All subjects had a 50\% chance of receiving the alcohol first. All subjects were shown to have mean peak blood alcohol concentration (BAC) levels of around $0.03 \%$. No significant differences were found between the two baselines. Significant increases in EEG magnitude occurred in the theta $(4-7.75 \mathrm{~Hz})$, alpha $1(8-9.75 \mathrm{~Hz})$ and beta $1(13.25-19.75 \mathrm{~Hz})$ spectrum in the frontal EEG regions, and alpha $1(8-9.75 \mathrm{~Hz})$ in the central and posterior regions. No significant changes were found in the theta $(4-7.75 \mathrm{~Hz})$ or beta $(13.5-30 \mathrm{~Hz})$ spectrums in the central and posterior regions. There were also no significant results for alpha $2(10-13 \mathrm{~Hz})$ in any of the regions. These results suggest that rapid cortical changes occur within the first 35 minutes after alcohol consumption.
\end{abstract}

Keywords: EEG, alcohol absorption phase, spectral EEG, environmental control systems 


\section{Introduction}

Ingestion of alcohol (ethanol) has been shown to be associated with changes in the characteristics of the awake EEG signal. These changes generally indicate a lowered cortical arousal or decreased EEG “activation” pattern (O’Boyle, Van, \& Hume, 1995; Stenberg et al., 1994). Most studies report patterns such as an overall increase in alpha and theta activity (Ehlers, Wall, \& Schuckit, 1989; Lukas, Mendelson, Woods, Mello, \& Teoh, 1989; Schwarz, Kielholz, Hobi, Goldeberg, Gilsdorf, Hofstetter et al., 1981), reduction in frequencies in the theta, fast alpha $(9-12 \mathrm{~Hz})$ and beta $(12-20 \mathrm{~Hz})$ bands (Ehlers et al., 1989), or an increase in only the slow alpha $(7.5-10 \mathrm{~Hz})$ wave component (Cohen, Porjesz, \& Begleiter, 1993). However, most of the abovementioned recent studies have concentrated on investigating the effects of alcohol after at least 35 minutes following ingestion.

Although it takes approximately one hour for $90 \%$ of the alcohol in a drink to be absorbed into the bloodstream (Grilly, 1994), it is also important to note that alcohol is rapidly and readily absorbed in the stomach, and that its subsequent accumulation in the brain is rapid enough to exert noticeable effects within minutes. As few recent studies have studied the initial influence of alcohol ingestion, there are good reasons for investigating the first 35 minutes following alcohol ingestion. For instance, the accumulation of alcohol in the brain is assumed to occur quite rapidly and it is also in this ascending phase of the $\mathrm{BAC}$ where alcohol has been reported to act as a stimulant, possibly via disinhibition (Schwarz et al., 1981). In addition, the effects of alcohol on the central nervous system (CNS) are said to be proportional to its concentration, though the effects are believed to be more marked when the concentration is rising than when it is falling (Gross, 1977; Kissin \& Begleiter, 1974; Wallgren \& Barry, 1970). This is known as the Mellanby effect (Mellanby, 1919; Moskowitz, Daily, \& Hendersen, 1979). The apparent cortical stimulation is a result of several factors such as a) reduced inhibitory control in parts of the brain, for 
instance, the reticular activating system and the cortex. b) The overshoot phenomenon, involves the time required for ethanol to distribute between the systemic circulation and the rest of the "body water". This results in an 'overshoot' of the BAC during the first 30 minutes (Hahn et al., 1997), whereas whole-body equilibrium distribution is maintained in the elimination phase, and c) acute pharmacodynamic tolerance, involving tolerance that develops within a single drinking session, in which alcohol induced impairment is greater when measured soon after beginning to drink than when it is measured at a later time.

Few studies have investigated the effects of alcohol on cortical activity in the ascending phase of alcohol absorption and so there is a limited understanding of its influence in the EEG over the entire cortex. A study by Schwarz and colleagues (1981) investigated the biphasic effects of alcohol. They found an increase in alpha wave power during the absorption (ascending BAC levels) phase, with a decrease in slow activity in the delta and theta bands. This was interpreted as a part of the stimulating-excitatory effect during the absorption phase, parallel to the increase in BAC. They also found a reverse pattern (increased theta and delta) in the first part of the elimination phase (descending BAC levels) reflecting the sedating, depressant action of alcohol in this phase. However, these findings were limited to one EEG channel, with bipolar configurations O1/CZ. Lukas et al., (1989) also explored the topographical changes in alpha activity from alcohol intoxication in women during the ascending phase (Lukas et al., 1989). They found that alcohol intoxication resulted in alpha activity increases in the entire scalp. However, their study was limited to results from one EEG band and they only studied females. Many previous studies investigating the effects of alcohol on the EEG have either limited the portion of the frequency spectrum (typically focusing on the EEG alpha band) or have limited the regions on the scalp by using small numbers of electrodes (Cohen et al., 1993). Consequently, the present study investigated alterations in the EEG pattern in the first 35 
minutes following alcohol consumption corresponding to the ascending phase of $\mathrm{BAC}$ levels.

\section{Methods}

\section{Participants}

Ten persons aged between 20 to 50 years volunteered to participate in the study. They were employees from a large tertiary institution and the sample was stratified for sex, so that five males and five females participated. In order to control for the influence of drug levels, only Caucasians within a body mass index (BMI) of 20-25 were selected. In addition, the selected participants had no medical history of any reactions to alcohol and were non-smokers. They also reported that they did not indulge in excessive or binge drinking of alcohol. That is, five reported they did not ingest alcohol regularly (less than one drink per day) and the other five reported having less than 2 drinks a day and all reported that their drinking was spread throughout the week. The 10 participants had a mean age of 34.1 years $(\mathrm{sd}=10.1)$, ranging from 23 to 49 years. The study was approved by the institutions research ethics committee and participants were only entered into the study after informed consent. All 10 subjects participated in a structured interview immediately prior to the study in order to determine health status. All were overtly free of viral or bacterial disease and reported no prior brain disease, psychopathology or neural injury. Participants also reported that they were not taking any medication that could potentially affect the recording of the EEG. Participants were asked to refrain from drinking any caffeine or alcohol for the 12 hours prior to recording sessions. For participant safety purposes, they were also asked to have breakfast two hours prior to the EEG recording sessions so that they would not have an empty stomach when they drank the alcohol. 


\section{Design}

The design involved a repeated measures randomized crossover design in which subjects acted as their own control. To ensure that changes in the EEG were due to alcohol and that baseline EEG was stable, two separate baselines were taken on consecutive days, one before the alcohol session and one before the placebo session. Participants attended two experimental sessions, where they were given a placebo or a defined dose of alcohol. The order in which the two conditions occurred for each participant was controlled by random allocation so that all subjects had a $50 \%$ chance of ingesting either the placebo or alcohol in the first instance.

In the alcohol condition, vodka (37.2\% alcohol by volume) was administered with a mixture of fresh orange juice, grapefruit juice and lemon/lime cordial. The fruit juice was added to disguise the taste of the alcohol. Doses for the alcohol study were determined by following the Widmark correction formula (based on alcohol to water ratio), which is: $0.54 \mathrm{~g}$ ethanol $/ \mathrm{kg}$ (for males) and $0.44 \mathrm{~g}$ ethanol $/ \mathrm{kg}$ (for females). This alcoholic drink was made up to $500 \mathrm{ml}$ with the fruit juice mixture. This was equivalent to 2 standard drinks for women and three standard drinks for men. The placebo consisted of the same three juices, but with water in place of the vodka. They were asked to finish their drink within 30 seconds. To determine the effectiveness of the placebo, immediately following the ingestion of the first drink participants were asked which drink they thought they were given, either the placebo or the alcohol drink. A breath analyzer, the Alcomaster SS-1093 (Australian Dynamic Technologies, Sydney, Australia) was used to measure levels of alcohol in the body.

During the alcohol and placebo conditions, EEG recordings commenced immediately after ingestion. BAC measured by the Alcomaster SS-1093, was taken after the 25-minute EEG measure and repeated every two minutes for 10 minutes to ensure that 
alcohol concentration no longer increased. Using this method, BAC levels for all 10 subjects were shown to stabilize before the last EEG measure at 35 minutes.

\section{EEG Procedure}

EEG data were recorded using the Neurosearch-24 system (Lexicor Medical Technologies, Boulder, CO, USA). All silver/silver chloride electrodes were referenced to linked earlobes and impedances were kept below $8 \mathrm{k} \Omega$. EEG data signals were acquired at a sampling rate of $128 \mathrm{~Hz}$ and the gain set at $16 \mathrm{~K}$ to ensure waveform resolution was not lost. All subjects were assessed for their EEG activity in sessions of two minutes, which included three consecutive measures of eyes closed (EC) and eyes open (EO). Because the study investigated frontal as well as posterior regions of the scalp, it was important to limit the amount of ocular artifact, therefore only EC data were used for the analyses.

Two minutes of EEG was recorded at each baseline, followed by two minutes at 5 minutes, 15 minutes, 25 minutes and 35 minutes for both the alcohol and placebo condition. Although 60 seconds of EC data was recorded, the ECS for the profoundly disabled is activated by the initial changes in EEG following eye closure, so only ten second EC intervals of data were used for the statistical analysis. In total, 50 seconds of EEG data was used for the analyses in the study, that is, 10 seconds over five measures. Ten seconds of data in each measure was thought by the researchers to provide an appropriate indication of EEG reactivity (Baving, Laucht \& Schmidt, 1999; Tran, Craig \& McIsaac, 2001). Because only one ten second EC period was used from each two-minute session in the analysis, it is important to demonstrate that the period chosen is not different to the other two EC periods. Reliability of the 10 second EC period was evaluated by randomly selecting one two minute recording session from the baseline, alcohol or placebo conditions for each subject and comparing the three EC periods for differences and similarities. The reliability of the 10-second EEG results in the three EC sessions was 
tested for differences using ANOVA and correlation analysis was also conducted to test for similarity in the three EC conditions.

EO data was recorded to provide intermission periods between the EC recordings as it is known that EEG alpha reactivity seldom persists for long without intermission (Adrian \& Matthews, 1934, Markand, 1990). As stated above, each recording session consisted of a total of two minutes of EEG activity and this was the equivalent of 60 twosecond epochs. The two-second epochs in the 10-second periods were then used for Fast Fourier Transform (FFT) analyses, with the spectral graph ranging from $0-30 \mathrm{~Hz}$ with a 0.5Hz-resolution. FFTs were performed using Exporter ${ }^{\circledR}$ software (Lexicor Medical Technologies, Boulder, CO, USA). To ensure that confounding results due to movement artifacts were minimized, a trained technician examined the EEG signal in the epochs for possible noise due to muscle activity or eye movement. Epochs contaminated by noise were removed to ensure that the signals being examined were free of artifact. This process eliminated around $10 \%$ of data.

FFT was applied to the artifact-free data in the 2-second epoch samples. Transformation yielded a value representing the total magnitude in each frequency band, expressed in microvolts $(\mu \mathrm{V})$. The first epoch following eye closure was not used since it may contain some ocular activity. The first five artifact-free epochs following EC were then averaged to give the total magnitude in each of five frequency bands including: theta (47.75Hz), alpha $1(8-9.75 \mathrm{~Hz})$, alpha $2(10-13 \mathrm{~Hz})$, beta1 $(13.25-19.75 \mathrm{~Hz})$ and beta2 $(20-$ $30 \mathrm{~Hz}$ ). These frequency bands were based on those used in the study by O'Boyle et al. (1995).

\section{Statistical analysis}

To test for the differences in the two baseline measures, repeated measures ANOVA was used. To test for changes in EEG activity following ingestion of alcohol or 
placebo within the first 35 minutes, repeated measures ANOVA was also performed. To test if the EEG activity in regions of the scalp changed differentially following ingestion of alcohol, sites in the regional areas of the scalp were grouped together and averaged. These areas included frontal (FP1, FP2, F3, F4, F7, F8 and FZ), central (C3, C4, CZ, T3 and T4) and posterior (P3, P4, PZ, O1, O2, T5 and T6) regions. Where there were overall significant results in the ANOVA, post-hoc comparisons (Scheffé test) were used to determine where differences occurred.

\section{Results:}

\section{Reliability}

The EEG in the 10 subjects was shown to vary little over the two consecutive days of the experiment and this was demonstrated by the lack of significant differences between the two baseline measures $(\mathrm{F}=0.06, \mathrm{df}=1,18, \mathrm{p}=\mathrm{n} . \mathrm{s})$. Furthermore, the 10 second $\mathrm{EC}$ periods used in the analysis were also shown to be representative of the other randomly chosen EC periods in the two minute recordings as there were no significant differences found between the three EC periods for all 10 subjects $(F=0.3, d f=2,18, p=n . s)$, and all EC periods were highly and significantly correlated ranging from 0.7 to 0.9 .

\section{BAC levels}

The mean BAC levels for the five males recorded between 25 and 35 minutes post ingestion was $0.038 \pm 0.014 \%$ (mean \pm S.D), and for the five females it was $0.026 \pm$ $0.0071 \%$. The BAC levels remained stable in the last 10-minute period for all subjects.

\section{Effectiveness of the placebo}

Immediately following the ingestion of the drink mixtures all subjects were asked whether they believed they had taken the placebo or alcohol drink. The effectiveness of the placebo was demonstrated with only $10 \%$ success rate in detecting the alcohol drink. 


\section{Changes in EEG signals from alcohol and placebo conditions}

The study investigated alcohol-induced changes in separate regions of the cortex, testing for differences between alcohol and placebo in the frontal, central and posterior regions. Figure 1.1 shows the significant changes in EEG magnitude in the regions of the cortex over the period from the beginning of testing (time 0) to 35 minutes. Tables 1.1 to 1.5 shows a breakdown of the EEG mean values and variance over time for the placebo and alcohol conditions in the three regions (frontal, central and posterior).

\section{Effects of alcohol on frontal regions}

In the frontal region, the only significant difference in EEG theta activity found was an interaction effect between groups over time. A significant interaction between the alcohol and placebo conditions occurred $(\mathrm{F}=3.32, \mathrm{df}=4,72, \mathrm{p}<0.02)$. Post-hoc Scheffé analyses found a significant $(\mathrm{p}<0.05)$ increase in theta activity occurred from baseline to the 35-minute recording in the alcohol condition while no significant changes in the placebo condition occurred over this period.

Alpha activity was shown to increase as a result of drinking alcohol. A significant difference over time $(\mathrm{F}=6.1, \mathrm{df}=4,72, \mathrm{p}<0.01)$ was found for alpha 1 in the frontal region. Post-hoc Scheffé analyses showed that these differences were between the baseline readings and data recorded at 25 minutes after ingestion, as well as between 5 and 25 minutes after ingestion. A significant 2-way interaction $(\mathrm{F}=6.64, \mathrm{df}=4,72, \mathrm{p}<0.01)$ between the alcohol and placebo conditions suggests these changes over time were due to drinking alcohol. While no significant alpha wave changes occurred during the placebo condition, post-hoc Scheffé analyses for the interaction revealed significant differences between baseline and data recorded at 15 minutes $(p<0.05), 25$ minutes $(p<0.01)$ and 35 minutes following alcohol ingestion $(\mathrm{p}<0.01)$. Differences were also found between alpha brain activity recorded at 5 minutes following alcohol ingestion and activity at 15 minutes 
$(p<0.05), 25$ minutes $(p<0.01)$ and 35 minutes following alcohol ingestion $(p<0.01)$. There were no significant differences between alcohol and placebo conditions for alpha 2 activity.

Beta 1 activity, only a significant interaction effect was found $(\mathrm{F}=4.31, \mathrm{df}=4,72$, $\mathrm{p}<0.01)$. The interaction effect suggests that beta 1 activity increased after ingesting alcohol, while no significant changes occurred during the placebo condition. However, post-hoc Scheffé analysis revealed no significant differences between data recorded at each of the times after alcohol ingestion.

\section{Effects of alcohol on central and posterior regions}

In the central and posterior regions, only the alpha 1 wave spectrum was shown to change significantly as a result of alcohol ingestion. A significant difference over time $(\mathrm{F}=3.6, \mathrm{df}=4,72, \mathrm{p}<0.01)$ was found for alpha 1 activity in the central region. Post-hoc Scheffé analyses showed that these differences were between the baseline reading and 25 minutes after ingestion. A significant interaction effect $(\mathrm{F}=7.09, \mathrm{df}=4,72, \mathrm{p}<0.01)$ suggests this difference was due to the ingestion of alcohol. A significant increase in alpha 1 activity occurred in the central regions in the alcohol condition while no significant change occurred in the placebo condition. Post-hoc Scheffé analyses showed that significant differences occurred between the baseline data and data recorded at 25 minutes $(\mathrm{p}<0.01)$ as well as 35 minutes $(\mathrm{p}<0.05)$, following alcohol ingestion. Significant differences also existed between data recorded at 5 minutes and 35 minutes following alcohol ingestion $(\mathrm{p}<0.01)$. In the posterior regions only a significant interaction effect was found for alpha 1 activity $(\mathrm{F}=4.71, \mathrm{df}=4,72, \mathrm{p}<0.01)$. Alpha 1 activity was significantly greater in the alcohol condition compared with placebo. Post-hoc Scheffé analyses showed that significance occurred between alpha 1 brain activity measured at baseline and 5 minutes, with data recorded at 25 minutes $(\mathrm{p}<0.05$ in both cases) following alcohol ingestion. No 
other significant changes for any other frequencies were found in the central and posterior sites.

\section{Discussion}

Despite suggestions that the accumulation of alcohol in the brain occurs almost immediately following ingestion, and that behavioral effects of alcohol occur before BAC peaks (Grilly, 1994), few studies have investigated changes in cortical activity during this time. To investigate the effects of alcohol on the CNS during this phase, a random order presentation of placebo and alcohol conditions was used and EEG was studied over the entire cortex. Initial analysis investigated the reliability of the baseline EEG measures and the EC EEG intervals. The results suggest the baselines were highly similar and that the EC sessions were representative of all EC sessions in the 2-minute recordings. This was expected since the resting EEG power is highly heritable (Strassen et al., 1988) with average heritabilities being $89 \%, 89 \%$ and $86 \%$ for theta, alpha and beta waves respectively (van Beijsterveldt et al., 1996).

The results of this investigation showed that significant and substantial cortical changes occurred in some components of the EEG within the first 35 minutes as a result of alcohol ingestion, while no significant EEG changes were found in the placebo group. Changes included a significant increase in theta, alpha 1, and beta 1 activity, especially in the EEG frontal regions. The increase in alpha 1 (or slow alpha) has been described as the primary EEG response to ethanol ingestion during the descending phase of alcohol absorption (Begleiter \& Platz, 1972; Davis et al., 1941; Doctor et al., 1966; Lukas, et al., 1986). The other common change in EEG reported during the descending phase is the increase in alpha activity accompanied by increases in theta activity (Ehlers et al., 1989; 
Lukas et al., 1989; Schwarz et al., 1981). Less commonly described are changes in beta activity as a result of alcohol ingestion (Stenberg et al., 1994).

The immediate change found following alcohol ingestion was lowered cortical arousal. The magnitude of theta and alpha 1 activity increased significantly in comparison to the placebo conditions in the frontal regions. Furthermore only alpha 1 activity showed significant increases in central and posterior regions. On the other hand there were no significant differences in the alcohol and placebo conditions for alpha 2. Ehlers et al. (1989) and Cohen et al. (1993) found similar results, though they only investigated cortical activity in the descending phase. Since alcohol only affected the slower alpha band, this could be interpreted as an alcohol induced shift of power from faster to slower frequencies and that participants are more likely therefore, to be drowsy during the alcohol sessions (Ehlers et al., 1989). Furthermore, the alcohol condition only modified the slower beta band (beta 1) as there were no significant changes in the beta 2 band in the placebo or alcohol conditions. Perhaps in a similar manner to the changes in alpha 1 , there was also a shift from the faster to slower frequencies in the beta bands.

It has been reported previously that increases in alpha activity after alcohol ingestion are most prominent when participants report to be feeling intense pleasure or euphoria (Lukas et al., 1986, Lukas et al., 1989). Likewise, the increases in alpha activity associated with alcohol consumption in this study may reflect the euphoric effects of alcohol commonly reported in the absorption phase. In their study, Lukas et al. (1989) also report an overall increase in alpha activity in all regions of the scalp in women. They also found that euphoric feelings were reported as most intense when alpha power in the frontal regions had increased the most. It was also interesting that EEG changes in this current study found significant and more prominent increases in alpha 1 activity in the frontal regions compared to the central and posterior regions. Similarly, Cohen et al. (1993) 
found increases in the slow alpha activity band in the F3, F4, C3, and C4 sites. However, they began recording after 35 minutes.

The results of the present investigation have shown substantial alcohol induced EEG theta, alpha 1 and beta 1 activity changes in the frontal cortex and alpha 1 changes in three regions (frontal, central and posterior), within 35 minutes of alcohol ingestion (during the absorption phase). These increases in activity may be a demonstration of the sedative effects of the alcohol. However, further research should study the influence of alcohol on EEG activity over longer periods of time so that both the ascending and the descending phases of the BAC curve can be examined over the entire cortex. 


\section{References}

Adrian E. D. and Matthews B. H. C. (1934) The Berger rhythm, potential changes from the occipital lobes in man. Brain 57: 355-385

Baving, L., Laucht, M., and Schmidt, M. H. (1999) Atypical frontal brain activation in ADHD: preschool and elementary school boys and girls. Journal of the American Academy of Child and Adolescent Psychiatry 38: 1363-1371.

Begleitter, H. and Platz, A. (1972) The effects of alcohol on the central nervous system in humans. In: Kissen B, Begleitter H, editors. The biology of alcoholism. Volume 2. New York: Plenum Press, pp. 293-343.

Cohen, H. L., Porjesz, B., and Begleiter, H. (1993). Ethanol-induced alterations in electroencephalographic activity in adult males. Neuropsychopharmacology 8: 365370.

Craig, A., Tran, Y., McIsaac, P., Moses, P., Kirkup, L., \& Searle, A. (200). The effectiveness of activating electrical devices using alpha wave synchronisation contingent with eye closure. Applied Ergonomics 31: 377-382.

Craig, A., Moses, P., Tran, Y., McIsaac, P., \& Kirkup, L. (2002). The effectiveness of a "hands free" environmental control system for the profoundly disabled. Arcbives of Physical Medicine and Rehabilitation 83: 1455-1458.

Davis, P.A., Gibbs, F. A., Davis, H., Jetter, W. W., and Trowbridge, L. S. (1941) The effects of alcohol upon the electroencephalogram (brain waves). Quarterly Journal of Studies on Alcohol 1: 626-637.

Doctor, R. F., Naitoh, P., and Smith, J. C. (1966) Electroencephalographic changes and vigilance behavior during experimentally induced intoxication with alcoholic subjects. Psychosomatic Medicine 28: 605-615. 
Ehlers, C. L., Wall, T. L., and Schuckit, M. A. (1989). EEG spectral characteristics following ethanol administration in young men. Electroencephalography and Clinical Neurophysiology 73: 179-187.

Grilly, D. M. (1994) Drugs and human behavior, 2nd ed. Massachusetts: Allyn and Bacon.

Gross, M. M. (1977) Alcohol intoxication and withdrawal, 1st ed. New York: Plenum Press.

Hahn, R. G., Norberg, A., and Jones A. W. (1997). 'Overshoot' of ethanol in the blood after drinking on an empty stomach. Alcohol 32: 501-505.

Herrmann, W. M. and Schaerer, E. (1986). Pharmaco-EEG: Computer EEG analysis to describe the projection of drug effects on a functional cerebral level in humans. In: Lopes da Silva FH, Storm van Leeuwen W, Remond A, editors. Handbook of Electroencephalography and Clinical Neurophysiology. Amsterdam: Elsevier Biomedical Press, pp 385-445.

Kissin, B. and Begleiter, H. (1974). The biology of alcoholism, 1st ed. New York: Plenum Press. Lukas, S. E., Mendelson, J. H., Benedikt, R. A. and Jones, B. (1986). EEG alpha activity increases during transient episodes of ethanol-induced euphoria. Pharmacology Biochemistry and Behaviour 25: 889-895.

Lukas, S. E., Mendelson, J. H., Woods, B. T., Mello, N. K. and Teoh, S. K. (1989) Topographic distribution of EEG alpha activity during ethanol-induced intoxication in women. Journal of Studies in Alcohol 50: 176-185.

Markand, O. N. (1990). Alpha rhythms. Journal of Clinical Neurophysiology 7: 163-189.

Mellanby, E. (1919) Alcohol: Its Absorption into and Disappearance from the Blood Under Different Conditions. Special Report Series no. 31. National Research Council, London. 
Moskowitz, H., Daily, J., and Henderson, R. (1979). The Mellanby effect in moderate and heavy drinkers. In: Johnston, I. R., editor. $7^{\text {th }}$ International Conference on Alcohol, Drugs and Traffic Safety, Melbourne Australia.

O'Boyle, D. J., Van, F., and Hume, K. I. (1995). Effects of alcohol, at two times of day, on EEG-derived indices of physiological arousal. Electroencephalography and Clinical Neurophysiology 95: 97-107.

Pihl, R. O. and Zacchia, C. (1986) Alcohol and aggression: a test of the affect-arousal hypothesis. Aggressive Behavior 12: 367-375.

Schwarz, E., Kielholz, P., Hobi, V., Goldberg, L., Gilsdorf, U., Hofstetter, M. et al. (1981) Alcohol induced biphasic background and stimulus-elicited EEG changes in relation to blood alcohol levels. International Journal of Clinical Pharmacology 19: 102-111.

Stassen, H. H., Lykken, D. T., Propping, P., and Bomben, G. (1988) Genetic determination of the human EEG. Survey of recent results on twins reared together and apart. Human Genetics 80: 165-176.

Stenberg, G., Sano, M., Rosén, I., and Ingvar, D. H. (1994). EEG topography of acute ethanol effects in resting and activated normals. Journal of Studies on Alcohol 55: 645-656.

Tran, Y., Craig, A., and McIsaac, P. (2001) Extraversion-introversion and 8-13 Hz waves in frontal cortical regions. Personality and Individual Differences 30: 205-215.

van Beijsterveldt, C. E., Molenaar, P. C, de Geus, E. J., and Boomsma, D. I. (1996) Heritability of human brain functioning as assessed by electroencephalography. American Journal of Human Genetics 58: 562-573.

Wallgren, H. and Barry, H. (1970). Actions of Alcohol. 3rd ed. New York: American Elsevier Publishing Co., Inc. 
Table 1.1 Shows a breakdown of mean values and variance over time for the placebo and alcohol conditions in frontal theta

\begin{tabular}{llccccc}
\hline Condition & & Mean & Standard & Standard & Confidence & Confidence \\
& & & Deviation & Error & $-\mathbf{9 5 \%}$ & $+\mathbf{9 5 \%}$ \\
\hline Placebo & Baseline & 9.58 & 1.95 & 0.62 & 8.19 & 10.97 \\
& $\mathbf{5}$ minutes & 9.07 & 1.54 & 0.49 & 7.96 & 10.17 \\
& $\mathbf{1 5}$ minutes & 8.95 & 2.16 & 0.68 & 7.41 & 10.49 \\
& $\mathbf{2 5}$ minutes & 9.25 & 1.90 & 0.60 & 7.89 & 10.60 \\
& $\mathbf{3 5}$ minutes & 8.78 & 3.15 & 0.99 & 6.53 & 11.04 \\
& Baseline & 9.38 & 2.01 & 0.64 & 7.95 & 10.82 \\
& $\mathbf{5}$ minutes & 8.70 & 1.77 & 0.56 & 7.43 & 9.96 \\
& $\mathbf{1 5}$ minutes & 10.25 & 2.91 & 0.92 & 8.16 & 12.33 \\
& $\mathbf{2 5}$ minutes & 10.06 & 2.91 & 0.92 & 7.97 & 12.14 \\
& $\mathbf{3 5}$ minutes & 11.66 & 3.61 & 1.14 & 9.08 & 14.25 \\
& & & & &
\end{tabular}


Table 1.2 Shows a breakdown of mean values and variance over time for the placebo and alcohol conditions in frontal alpha 1

\begin{tabular}{|c|c|c|c|c|c|c|}
\hline \multirow[t]{2}{*}{ Condition } & & \multirow[t]{2}{*}{ Mean } & \multirow{2}{*}{$\begin{array}{l}\text { Standard } \\
\text { Deviation }\end{array}$} & \multirow{2}{*}{$\begin{array}{l}\text { Standard } \\
\text { Error }\end{array}$} & \multirow{2}{*}{$\begin{array}{l}\text { Confidence } \\
-95 \%\end{array}$} & \multirow{2}{*}{$\begin{array}{l}\text { Confidence } \\
+95 \%\end{array}$} \\
\hline & & & & & & \\
\hline \multirow[t]{5}{*}{ Placebo } & Baseline & 11.93 & 4.43 & 1.40 & 8.76 & 15.09 \\
\hline & 5 minutes & 11.57 & 4.18 & 1.32 & 8.58 & 14.57 \\
\hline & 15 minutes & 10.60 & 3.95 & 1.25 & 7.77 & 13.42 \\
\hline & 25 minutes & 12.28 & 5.38 & 1.70 & 8.43 & 16.13 \\
\hline & 35 minutes & 11.06 & 5.62 & 1.78 & 7.03 & 15.08 \\
\hline \multirow[t]{5}{*}{ Alcohol } & Baseline & 11.57 & 4.80 & 1.52 & 8.13 & 15.00 \\
\hline & 5 minutes & 11.45 & 6.48 & 2.05 & 6.81 & 16.08 \\
\hline & 15 minutes & 14.42 & 6.24 & 1.97 & 9.96 & 18.88 \\
\hline & 25 minutes & 16.06 & 6.77 & 2.14 & 11.21 & 20.90 \\
\hline & 35 minutes & 15.59 & 7.78 & 2.46 & 10.02 & 21.15 \\
\hline
\end{tabular}


Table 1.3 Shows a breakdown of mean values and variance over time for the placebo and alcohol conditions in central alpha 1

\begin{tabular}{|c|c|c|c|c|c|c|}
\hline \multirow[t]{2}{*}{ Condition } & & \multirow[t]{2}{*}{ Mean } & \multirow{2}{*}{$\begin{array}{l}\text { Standard } \\
\text { Deviation }\end{array}$} & \multirow{2}{*}{$\begin{array}{l}\text { Standard } \\
\text { Error }\end{array}$} & \multirow{2}{*}{$\begin{array}{l}\text { Confidence } \\
-95 \%\end{array}$} & \multirow{2}{*}{$\begin{array}{l}\text { Confidence } \\
+95 \%\end{array}$} \\
\hline & & & & & & \\
\hline \multirow[t]{5}{*}{ Placebo } & Baseline & 11.45 & 3.80 & 1.20 & 8.73 & 14.17 \\
\hline & 5 minutes & 11.73 & 4.19 & 1.33 & 8.73 & 14.73 \\
\hline & 15 minutes & 9.83 & 3.66 & 1.16 & 7.22 & 12.45 \\
\hline & 25 minutes & 11.03 & 4.76 & 1.51 & 7.62 & 14.44 \\
\hline & 35 minutes & 10.04 & 4.91 & 1.55 & 6.52 & 13.55 \\
\hline \multirow[t]{5}{*}{ Alcohol } & Baseline & 10.44 & 4.51 & 1.43 & 7.21 & 13.66 \\
\hline & 5 minutes & 10.96 & 5.68 & 1.79 & 6.90 & 15.02 \\
\hline & 15 minutes & 12.63 & 5.52 & 1.75 & 8.68 & 16.58 \\
\hline & 25 minutes & 15.54 & 6.06 & 1.92 & 11.20 & 19.87 \\
\hline & 35 minutes & 14.06 & 6.31 & 1.99 & 9.55 & 18.57 \\
\hline
\end{tabular}


Table 1.4 Shows a breakdown of mean values and variance over time for the placebo and alcohol conditions in posterior alpha 1

\begin{tabular}{|c|c|c|c|c|c|c|}
\hline \multirow[t]{2}{*}{ Condition } & & \multirow[t]{2}{*}{ Mean } & \multirow{2}{*}{$\begin{array}{l}\text { Standard } \\
\text { Deviation }\end{array}$} & \multirow{2}{*}{$\begin{array}{l}\text { Standard } \\
\text { Error }\end{array}$} & \multirow{2}{*}{$\begin{array}{l}\text { Confidence } \\
-95 \%\end{array}$} & \multirow{2}{*}{$\begin{array}{l}\text { Confidence } \\
+95 \%\end{array}$} \\
\hline & & & & & & \\
\hline \multirow[t]{5}{*}{ Placebo } & Baseline & 16.81 & 8.93 & 2.82 & 10.43 & 23.20 \\
\hline & 5 minutes & 17.74 & 10.43 & 3.30 & 10.28 & 25.20 \\
\hline & 15 minutes & 15.04 & 8.21 & 2.59 & 9.17 & 20.91 \\
\hline & 25 minutes & 15.65 & 9.89 & 3.13 & 8.58 & 22.73 \\
\hline & 35 minutes & 14.44 & 10.07 & 3.19 & 7.23 & 21.65 \\
\hline \multirow[t]{5}{*}{ Alcohol } & Baseline & 15.90 & 11.29 & 3.57 & 7.82 & 23.98 \\
\hline & 5 minutes & 15.99 & 11.53 & 3.65 & 7.74 & 24.24 \\
\hline & 15 minutes & 18.39 & 11.21 & 3.55 & 10.37 & 26.41 \\
\hline & 25 minutes & 21.77 & 11.97 & 3.79 & 13.21 & 30.34 \\
\hline & 35 minutes & 19.96 & 10.64 & 3.36 & 12.35 & 27.57 \\
\hline
\end{tabular}


Table 1.5 Shows a breakdown of mean values and variance over time for the placebo and alcohol conditions in frontal beta 1

\begin{tabular}{|c|c|c|c|c|c|c|}
\hline \multirow[t]{2}{*}{ Condition } & & \multirow[t]{2}{*}{ Mean } & \multirow{2}{*}{$\begin{array}{l}\text { Standard } \\
\text { Deviation }\end{array}$} & \multirow{2}{*}{$\begin{array}{l}\text { Standard } \\
\text { Error }\end{array}$} & \multirow{2}{*}{$\begin{array}{l}\text { Confidence } \\
-95 \%\end{array}$} & \multirow{2}{*}{$\begin{array}{l}\text { Confidence } \\
+95 \%\end{array}$} \\
\hline & & & & & & \\
\hline \multirow[t]{5}{*}{ Placebo } & Baseline & 10.51 & 3.13 & 0.99 & 8.27 & 12.75 \\
\hline & 5 minutes & 11.36 & 3.75 & 1.19 & 8.68 & 14.04 \\
\hline & 15 minutes & 10.70 & 3.69 & 1.17 & 8.06 & 13.34 \\
\hline & 25 minutes & 10.39 & 3.80 & 1.20 & 7.67 & 13.11 \\
\hline & 35 minutes & 9.73 & 3.31 & 1.05 & 7.36 & 12.10 \\
\hline \multirow[t]{5}{*}{ Alcohol } & Baseline & 10.33 & 3.29 & 1.04 & 7.98 & 12.69 \\
\hline & 5 minutes & 11.21 & 4.52 & 1.43 & 7.98 & 14.44 \\
\hline & 15 minutes & 11.02 & 4.39 & 1.39 & 7.89 & 14.16 \\
\hline & 25 minutes & 12.44 & 5.90 & 1.86 & 8.22 & 16.66 \\
\hline & 35 minutes & 12.86 & 4.54 & 1.43 & 9.61 & 16.10 \\
\hline
\end{tabular}


Figure 1 shows the influence of alcohol on EEG magnitude in comparison to the placebo condition in cortical regions in which significant differences were found. The non-filled circles show EEG changes from the placebo condition over time and the black filled squares show EEG changes from the alcohol condition over time. 


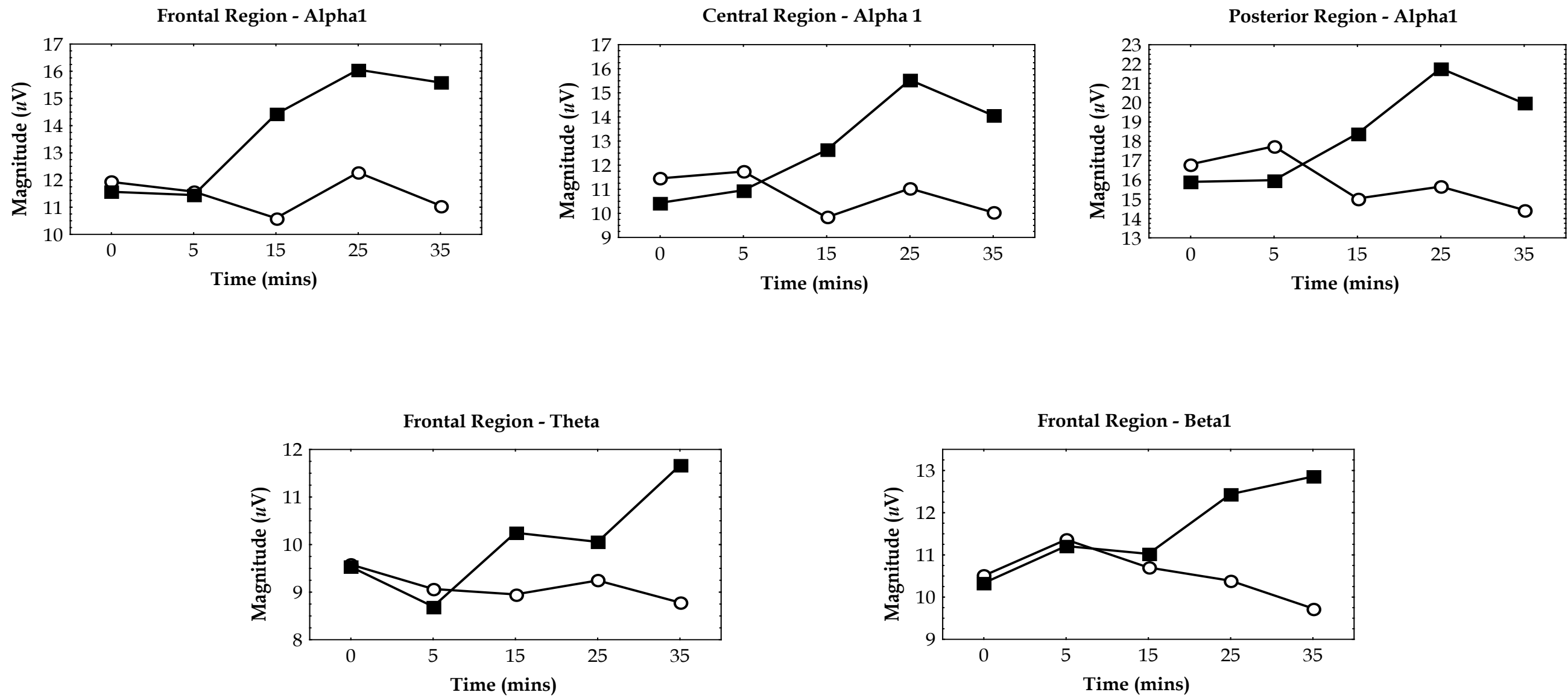